\title{
Os Benefícios Pessoais da Pós-Graduação Stricto Sensu: uma Análise na Percepção de Mestres em Contabilidade
}

\section{Resumo}

Níveis mais altos de instrução geram benefícios econômicos maiores, segundo a teoria do Capital Humano. Os benefícios pessoais, para o mestrado, são importantes, pois podem ser utilizados como evidências para tomada de decisão do candidato ao curso, do governo e do gestor do próprio curso. O objetivo geral é avaliar o benefício da pós-graduação stricto sensu, no âmbito pessoal, segundo a percepção de seus egressos. O levantamento, limitado a mestres egressos respondentes da Universidade Federal de Santa Catarina, avalia as situações de benefícios com auxílio de coeficientes de variação. Os benefícios financeiros variaram de 0,54 até 9,65 salários mínimos mensais, com média ponderada de 3,19 salários mínimos mensais. Houve variação significativa na renda após o curso para $43,48 \%$ dos mestres. O mestrado gerou benefício financeiro efetivo apenas em três circunstâncias: mestres que possuem também o doutorado; mestres com cargos públicos que remuneram mais por possuir títulos; e mestres que auferiam rendas baixas antes do mestrado e hoje atuam somente na docência.

Palavras-chave: Pós-graduação. Teoria do Capital Humano. Economia da Educação.

\author{
Tiago Guimarães Barth \\ Mestrado em Contabilidade pela \\ Universidade Federal de Santa Catarina \\ (UFSC) e Técnico Administrativo em \\ Educação na Universidade Federal do Mato \\ Grosso do Sul (UFMS). Contato: Cidade \\ Universitária, $\mathrm{S} / \mathrm{N}$. Universitário. Campo \\ Grande-MS. CEP.: 79070-900. \\ E-mail: tiagobarth85@gmail.com

\section{Sandra Rolim Ensslin} \\ Doutora pela Universidade Federal de Santa \\ Catarina (UFSC) e Pós-Doutorado pela \\ Universidade de Valência e Professora da \\ Universidade Federal de Santa Catarina \\ (UFSC). Contato: Centro Socioeconômico - \\ Departamento de Ciências Contábeis, \\ Sala 109. Trindade. Florianópolis-SC. \\ CEP.: 88040-970. \\ E-mail: sensslin@gmail.com
}

\section{Altair Borgert}

Doutor pela Universidade Federal de Santa Catarina (UFSC) e Professor da Universidade Federal de Santa Catarina (UFSC). Contato: Campus Universitário, CSE/CCN. Trindade. Florianópolis-SC. CEP.: 88040-970. E-mail: altair@borgert.com.br 


\section{Introdução}

A educação geralmente é uma boa maneira de garantir e aumentar a renda das pessoas. No Brasil, o aumento de renda pessoal advindo da educação superior (bônus educacional) é o maior entre os 32 países analisados pela OECD, bem como é $50 \%$ maior do que o país segundo colocado (Hungria) no mesmo ranking (OECD, 2013). O bônus educacional é atraente e incentiva a realização de investimentos em educação no País, mas, por outro lado, revela a falta de trabalhadores devidamente qualificados no mercado. Um estudo recente mostra que os brasileiros cujo nível de instrução mais elevado é o mestrado recebem remuneração média $84 \%$ superior aos que apenas concluíram o curso superior (CENTRO DE GESTÃO E ESTUDOS ESTRATÉGICOS - CGEE, 2013).

Salvato, Ferreira e Duarte (2010) observam, diante dos dados de diferentes regiões brasileiras, que, de fato, a renda é diretamente proporcional à escolaridade, o que reforça a ideia de que o diferencial de renda pode ser explicado pela diferença de anos de instrução ou escolaridade.

Em países desenvolvidos, as políticas educacionais estão adotando abordagens econômicas em resultados de ensino e pesquisa. Ocorre então um aumento na demanda por políticas educacionais baseadas em evidências, ou seja, investimentos maiores ou menores em determinado campo só são possíveis com a evidência de resultados (Machin, 2014)

De acordo com a política baseada em evidências, o Governo pode então tomar suas decisões, com base no agrupamento de informações advindas dos produtos (egressos) e resultados de cada área e programa de educação (Chapman, 2013).

O Governo brasileiro prevê, mediante o Plano Nacional de Educação (2011-2020), no âmbito da educação superior, uma elevação da qualidade pela ampliação da atuação de mestres e doutores nas instituições de educação superior para $75 \%$, no mínimo, do corpo docente em efetivo exercício, dos quais $35 \%$ devem ser doutores.

Mais especificamente na pós-graduação stricto sensu em Contabilidade Brasileira, foi identificado um estudo que contribui com evidências de fatores que se alteram com os títulos de mestrado e doutorado em Contabilidade. Cunha (2007) utilizou um grupo de experts em sua tese de doutorado, com a técnica Delphi, para chegar a fatores como respeitabilidade; reconhecimento acadêmico e profissional; diferenciação profissional; espírito acadêmico; amadurecimento pessoal; produção acadêmica; oportunidades na carreira; autonomia profissional; habilidades cognitivas; competências analíticas; empregabilidade; prestígio; produtividade; mobilidade profissional; responsabilidade social; status; remuneração; promoção social; estabilidade profissional; estilo de vida; e realização/satisfação pessoal que se alteram com o título de doutorado em Contabilidade. Esses fatores podem ser entendidos também como possíveis benefícios pessoais obtidos com o curso.

Essas informações provenientes dos produtos da pós-graduação em Contabilidade (egressos) podem ser utilizadas como evidências para tomada de decisões, seja por parte do Governo, do programa ou do candidato ao curso. Para tal, precisam ter a qualidade, a amplitude e a confiabilidade para que possam servir de referência.

É importante que haja estudos em diversos programas de pós-graduação em Contabilidade para fins de comparação de resultados e abordagens do problema.

Em função do campo de atuação, da área de conhecimento, da região, entre outros, os benefícios podem ser menos ou mais atrativos. Neste sentido, propõe-se a seguinte questão: Qual é o benefício da pós-graduação stricto sensu, no âmbito pessoal, segundo a percepção de seus egressos?

Para responder à pergunta de pesquisa, tem-se como objetivo geral avaliar o benefício da pós-graduação stricto sensu, no âmbito pessoal, segundo a percepção de seus egressos.

Os critérios de importância, originalidade e viabilidade também são observados (Castro, 1977).

A importância para o desenvolvimento do estudo é a contribuição com percepções a respeito da teoria do Capital Humano e da economia da educação no âmbito da pós-graduação e também no contexto social, pois é necessário oferecer subsídios para que possíveis interessados na pós-graduação stricto 
sensu em Contabilidade optem, ou não, por cursá-la, com base em evidência de resultados e dados cientificamente comprovados. Esse estudo ajuda também na avaliação de investimentos no curso, além do processo de seleção, pelo menos nesta pós-graduação stricto sensu.

A presente pesquisa é original, uma vez que não foram identificados estudos que tratem dos benefícios da pós-graduação stricto sensu em Contabilidade, embora alguns apresentem fatores que se alteram com o título de doutorado e mestrado e outros que trazem uma ideia do retorno financeiro pessoal do investimento em mestrado de maneira geral.

O critério de viabilidade é atendido pelo acesso aos contatos de egressos e ferramentas utilizadas.

Cumpre esclarecer que a presente pesquisa está delimitada a investigar o Programa de Pós-Graduação Stricto Sensu em Contabilidade da Universidade Federal de Santa Catarina situada na região Sul do Brasil.

Em relação ao horizonte temporal, a pesquisa é realizada com os mestres respondentes formados desde a fundação do curso, em 2004, até 7 de julho de 2014.

\section{Referencial Teórico}

\subsection{A Teoria do Capital Humano}

A Teoria do Capital Humano explica a relação educação, trabalho e renda. A educação tem papel importante no aumento das modalidades de trabalho, na produtividade e na renda dos trabalhadores.

Lima (1980) explica a Teoria do Capital Humano com sua sistemática. Os indivíduos procuram a educação, pois ela tem o efeito principal de mudar suas habilidades e conhecimentos. Com o aumento da instrução, a habilidade cognitiva e a produtividade também aumentam. Assim, com o aumento da produtividade as pessoas podem receber maiores rendas, o que gera mais capital.

Entre os primeiros estudos mais conhecidos e citados a respeito da Teoria do Capital Humano, têm-se os de Schultz (1961), que defendeu a compatibilidade entre dignidade e liberdade, com o entendimento de que o homem pode ser visto como capital; Becker (1964), que aplicou a Teoria da Utilidade na relação entre educação e capital humano; e Mincer (1958) que identificou os aumentos de renda advindos da educação. Há ainda outros trabalhos, como os de Blaug (1976) e Ben-Porath (1967), que contribuem com alternativas, demonstrando as razões dos investimentos na instrução das pessoas.

Frigotto (2003) sugere que um acréscimo marginal na instrução, treinamento e educação corresponde a um acréscimo marginal na capacidade de produção do indivíduo. A ampliação de habilidades e a melhora da qualidade do trabalho são modalidades de investimento que têm como base de sustentação a educação.

Para Machin e Stevens (2004), a Teoria do Capital Humano pode ser entendida como um investimento na educação, aumentando a produtividade futura do indivíduo e trazendo outros benefícios privados e sociais. As estimativas dos retornos privados e sociais da educação e da eficácia dos cursos podem ser usadas para orientar a alocação de recursos no setor público, na tomada de decisão por parte de candidatos e também pela coordenação dos cursos.

Robeyns (2006) explica que a Teoria do Capital Humano é vinculada, essencialmente, a mudanças econômicas (aumento de renda e crescimento da economia), além de ser exclusivamente instrumentalista. A autora defende que os benefícios e as capacidades provenientes da educação são, na teoria, modelos multidimensionais e abrangentes, que desenvolvem várias funções também intrínsecas e não somente econômicas. O objetivo intrínseco das políticas educacionais é desenvolver a capacidade social das pessoas; a economia, nesse caso, pode ser apenas consequência.

\subsection{Benefícios da educação}

A partir do final da última década, os estudos relacionados à economia da educação cresceram exponencialmente. Machin (2014) aponta seis razões para o aumento de pesquisas em economia da edu- 
cação: aumento de níveis mais elevados de ensino; uma base crescente que evidencia o investimento em educação como sinônimo de desenvolvimento econômico e de resultados sociais cada vez mais amplos ao longo do tempo; outras áreas pesquisando sobre o tema educação/economia; as inovações metodológicas que estão se adequando melhor a diversas questões que envolvem a economia da educação; uma maior e melhor qualidade de dados; e a busca de políticas educacionais baseadas em evidências.

Lordêlo e Verhine (2001) abordaram os benefícios econômicos de investimentos individuais e sociais em cursos de mestrado e doutorado para professores do ensino universitário. Os resultados demonstraram que os cursos são ótimas opções de investimento para o mercado de ensino superior, com exceção dos profissionais que têm dedicação parcial às instituições e múltiplos vínculos empregatícios que implicam alta renda sacrificada ao se optar pelos cursos. Entretanto, mesmo para essas exceções, o curso pode ter sido positivo em termos psicológicos e sociais.

Segundo Coates e Edwards (2011), na Austrália, o salário médio dos empregados com pós-graduação aumentou de $\$ 38.000$ dólares para $\$ 60.000$ dólares australianos nos primeiros cinco anos de conclusão do curso (aumento de 58\%). No período de cinco anos, o salário, para 50\% dos titulados, variou de U\$47.726 para U\$78.000. É um resultado favorável, se comparado o salário médio, que era de U\$46.332, para todos os trabalhadores na Austrália daquele momento.

Oreopoulos e Salvanes (2011) explicam que o retorno social proveniente da educação pode ser muito maior do que o financeiro, que é o foco de grande parte dos estudos vinculados a economia da educação. Nesse sentido, os retornos sociais talvez não estejam sendo levados em conta como deveriam, já que são tão grandes, ou até maiores do que o efeito da educação sobre os rendimentos financeiros.

Menon, Pashourtidou, Plycarpoue Pashardes (2012) - concluíram que graduados que completaram a pós-graduação possuem uma melhor chance de encontrar emprego depois da formatura do que os outros. Este resultado sugere que os alunos tendem a subestimar os benefícios potenciais de uma pós-graduação, no que diz respeito à probabilidade de emprego pelo menos.

O presente estudo se delimita a área contábil, que também possui alguns estudos relacionados a benefícios da pós-graduação em Contabilidade, explicitados a seguir.

Martins e Monte (2009b) traçaram um perfil dos mestres egressos do Programa Multi-institucional e Inter-Regional de Pós-Graduação em Ciências Contábeis da UnB/UFPB/UFPE/UFRN, cuja remuneração média percebida pelos respondentes no momento de seu ingresso era de $\mathrm{R} \$ 3.968,31$ (76,04\% composta pelas atividades relacionadas ao mercado e $23,96 \%$ pelas atividades relacionadas à academia). Já a remuneração média dos mestres em Ciências Contábeis, no ano de 2009, era de R \$7.486,97, ainda composta, em sua maioria, pela remuneração proveniente do mercado $(67,44 \%)$.

Cunha, Cornachione Junior e Martins (2010) identificaram alterações significativas em 19 fatores influenciáveis pela titulação de doutorado em Ciências Contábeis, inclusive sociais, obtidos a partir da consulta a especialistas, utilizando a técnica Delphi. Todos os fatores sociais e econômicos (respeitabilidade, reconhecimento acadêmico e profissional, diferenciação profissional, espírito acadêmico, amadurecimento pessoal, produção acadêmica, oportunidades na carreira, autonomia profissional, habilidades cognitivas, competências analíticas, empregabilidade, prestígio, produtividade, mobilidade profissional, responsabilidade social, status, remuneração, promoção social, estabilidade profissional, estilo de vida e realização/satisfação pessoal) foram avaliados positivamente pelos egressos daquele doutorado, embora alguns em menor intensidade.

Este é um dos poucos trabalhos existentes no que diz respeito às inter-relações entre níveis mais altos de instrução e benefícios sociais e econômicos para o aluno/egresso. Ao ingressarem no doutorado, os pesquisados buscavam seguir ou aprimorar a carreira de pesquisador, além da obtenção de melhor nível de renda, entre outros fatores. Os efeitos da titulação foram observados na qualidade de vida e nas oportunidades profissionais e sociais. Quanto aos rendimentos, foram bastante acentuados: $41,5 \%$ auferiam renda de até $\mathrm{R} \$ 5.000$ no ingresso do doutorado, já na data daquela pesquisa, 93,1\% dos doutores auferiam renda superior a $\mathrm{R} \$ 5.000$. 
Martins e Monte (2010) investigaram as motivações, expectativas e influências relacionadas à obtenção do título de mestre em Ciências Contábeis, pelo Programa Multiinstitucional e Inter-Regional de Pós-Graduação em Ciências Contábeis da UnB/UFPB/UFPE/UFRN, com base nas avaliações e percepções de seus egressos.

Os autores utilizaram como fundamentação teórica a Teoria do Capital Humano, a pós-graduação stricto sensu em nível de mestrado no Brasil e a pós-graduação em Ciências Contábeis. Os resultados demonstraram que as principais variáveis que motivaram os respondentes a ingressarem no mestrado foram a "obtenção de mais conhecimentos", a "obtenção de diferenciação profissional" e a "ampliação das oportunidades de emprego".

Quando titulados, os egressos tiveram como principal expectativa atingida a "obtenção de mais conhecimento", seguida pela "ampliação da formação geral" e pela "capacitação em pesquisa".

Também investigaram os principais fatores influenciados pelo título, quais sejam: amadurecimento profissional; respeitabilidade e reconhecimento acadêmico/profissional; e espírito acadêmico. Uma das conclusões foi que o título influencia positivamente o desempenho acadêmico e profissional dos egressos, ratificando os pressupostos da Teoria do Capital Humano quanto ao aumento de sua empregabilidade, produtividade e rendimento potencial.

Dallabona, Oliveira e Rausch (2013) identificaram os avanços pessoais e profissionais dos egressos do Programa de Pós-Graduação em Ciências Contábeis da Universidade Regional de Blumenau relacionados à obtenção do título de mestre.

Da amostra de 48 mestres titulados, 17 têm menos de cinco anos de experiência na docência. Após titulação, 38 mestres lecionam em instituições privadas, sendo que 17 se dedicam à docência em tempo integral. Outros resultados indicam melhora na remuneração salarial após a titulação, em que 31 respondentes recebem acima de $\mathrm{R} \$ 4.905,00$. A maior parte dos mestres participa de atividades envolvendo pesquisas, projetos de extensão e possui cargos administrativos e diretivos em instituições de ensino.

Os autores também investigaram os fatores que pesaram na decisão pelo mestrado e a influência da titulação de mestre no desempenho acadêmico-profissional. Uma das conclusões foi que de forma geral, o título de mestre proporcionou avanços pessoais e profissionais aos egressos do mestrado em Ciências Contábeis.

\section{Metodologia}

\subsection{Procedimentos metodológicos}

O objetivo geral, o problema de pesquisa, a concepção filosófica (positivista), o tipo de estratégia (levantamento) e os métodos para realização dessa estratégia (questionários e análise estatística) informam uma abordagem quantitativa (Creswell, 2010). Martins e Theóphilo (2007) explicam que o estudo quantitativo organiza, sumariza, caracteriza e interpreta os dados numéricos coletados.

Segundo Gil (2002), as vantagens dos levantamentos (surveys) são o conhecimento direto da realidade, economia, rapidez e quantificação.

A população-alvo do estudo compreende todos os mestres do PPGC até 7 de julho de 2014. A quantidade de mestres somou 91 titulados. São considerados todos os mestres formados desde a fundação do curso. Como a população é pequena, procura-se realizar um censo geral.

A quantidade de questionários efetivamente respondidos foram 46, não permitindo a generalização das análises de resultados e conclusões, que, além disso, são exclusivas do mestrado em Contabilidade da UFSC, ou seja, não servem para generalizações desta e de outras populações, o que denota a limitação da presente pesquisa. A finalidade é de obter parâmetros, comparações e conhecer as situações de possíveis benefícios pessoais.

A pesquisa é realizada em um determinado período de tempo. Devido a estas limitações, os resultados são um recorte da realidade do problema e não podem ser considerados como respostas definitivas ao problema. Devido à importância do estudo e escassez de pesquisas semelhantes, as limitações da população, acesso a egressos de outros programas, de outras regiões e período temporal não invalidam o estudo. 


\subsection{Procedimentos para revisão da literatura}

Procedeu-se a uma sistematização para seleção dos artigos relacionados ao tema de pesquisa. A finalidade foi obter os estudos já desenvolvidos, com base no ProKnow-C (Ensslin, Ensslin, Lacerda \& Tasca, 2010; Bortoluzzi, Ensslin, Ensslin \& Valmorbida, 2011; Lacerda, Ensslin \& Ensslin, 2012; Ensslin, Ensslin \& Pinto, 2013; Ensslin, Ripoll-Feliu, Ensslin \& Dutra, 2014; Tasca, Ensslin, Ensslin \& Alves, 2010; Silva, Ensslin, Ripoll-Feliu \& Soler, 2014).

O período de coleta dos artigos ocorreu no mês de maio de 2013, com atualização em setembro de 2014, todos disponíveis eletronicamente.

Por fim, a leitura na íntegra dos artigos alinhados resultou no material que contribuiu para a construção do referencial teórico utilizado neste trabalho e serviu de apoio para as demais seções.

Na composição das seções, foram utilizadas referências citadas nos artigos que compõe o portfólio, mas somente nos casos em que o autor obteve acesso à fonte original. Alguns estudos não provenientes do rastreamento também foram citados, por serem considerados relevantes e/ou úteis na construção deste estudo.

\subsection{Procedimentos para coleta e análise de dados}

Os questionários foram encaminhados via e-mail, com uma breve apresentação. Após uma semana, encaminhou-se novamente um lembrete para os que ainda não haviam respondido, a fim de obter um maior número de respondentes. Houve também a tentativa com e-mails alternativos dos egressos através da Plataforma Lattes. Em casos de maior dificuldade de localização, optou-se também pelo contato telefônico ou via rede social.

Foi realizado o pré-teste dos questionários para avaliar sua funcionalidade e também a qualidade dos dados, visando verificar também correlações possíveis e consistência. Em seguida, o questionário foi testado, mas, desta vez, com a amostra do estudo, a fim de consolidar o instrumento de pesquisa com uma construção mais confiável da cadeia de evidências. Os dados coletados dos questionários foram tabulados e tratados no software Excel ${ }^{\circ}$. Coleta e análise neste tipo de estudo são indissociáveis pela imprevisão de correlações e características associativas das variáveis analisadas.

Pozzebon e Freitas (1998) explicam que a exploração dos relacionamentos entre variáveis pode gerar diferenças, similaridades e correlações que formam diferentes categorias. Com isso, há maior riqueza na construção de uma cadeia de evidências. Para tal, o contexto de cada situação não pode ser perdido. Assim é possível inferir associações entre as categorias e alcança-se consistência e confiabilidade nos resultados.

Do ponto de vista financeiro, constrói-se uma equação $Z_{i}=\beta_{1} X_{1}-\beta_{2} X_{2}+\varepsilon_{i}$ onde $Z_{i}$ é a variável dependente de benefícios econômicos totais que é explicada basicamente por duas variáveis independentes $\left(X_{1}, X_{2}\right)$. A variável independente $X_{1}$ simboliza a renda posterior à titulação, enquanto que $X_{2}$ é a renda do candidato ao mestrado (anterior ao ingresso). $\beta_{1}$ e $\beta_{2}$ são os parâmetros que são estimados conforme os resultados dos grupos (i) e também pelo tempo de carreira (tempo de contribuição ou idade trabalhista). $\varepsilon_{i}$ representa o efeito do erro aleatório de possíveis observações ou variáveis não contempladas pelo modelo proposto e representa também uma limitação do modelo proposto. Esse sistema visa avaliar também as hipóteses de viabilidade financeira para os possíveis grupos de egressos da pós-graduação.

No teste, e também no início da análise dos dados, procedeu-se à investigação de características dos sujeitos da pesquisa ou das respostas que levam a discrepâncias nos resultados. Para tratar essas discrepâncias, foram utilizados testes de Coeficiente de Variação tanto na coleta quanto na análise.

Semaan, Cruz, Brito e Ochi (2012) sugerem que a análise por clusters pode ser aplicada com o objetivo de identificar grupos dentro de um conjunto de dados, ou identificar o número ideal de grupos mediante avaliação de algum índice ou coeficiente. A finalidade dessa abordagem é gerar resultados e conclusões mais precisas e bem fundadas. 
Ainda segundo Pozzebon e Freitas (1998) pesquisas que envolvem modelagem e dados quantitativos devem dar importância ao processo de explicar com clareza os métodos, apresentar cada passo e declarar os pressupostos, lógicas e escolhas utilizadas na condução de cada investigação. Busca-se atender a esse argumento para que a pesquisa possa ser replicada em outros estudos.

Ressalta-se que os procedimentos adotados tiveram por objetivo minimizar distorções nas rendas diversas (docente, mercado) e nos diversos períodos (antes, durante e após o mestrado). Essas distorções de tempo, inflação e salário mínimo anual, na maioria dos estudos identificados, não parecem ter sido levadas em consideração, dando a impressão de que os benefícios financeiros são "fantásticos" quando, na realidade, podem ser em grande parte variações temporais.

Só após tabular todos os valores atualizados para o ano de 2014 é que procedeu-se à análise dos dados. Para questões que envolviam rendas anteriores e posteriores ao curso de mestrado, calcularam-se a correlação de Pearson e o teste econométrico de diferença entre duas médias. Este teste teve como objetivo investigar se as diferenças entre as médias das variáveis de rendas anteriores e posteriores são estatisticamente significativas. O intervalo de confiança utilizado foi $90 \%(\alpha=0,1)$ para todas as variáveis e a estatística foi a $t$ de Student.

Também são observadas variações nas rendas anteriores e posteriores, por estratos sociais, conforme a classificação do IBGE, como forma alternativa e também para fins de comparação de abordagens.

Apesar disso, a Teoria do Capital Humano poderia não se provar para determinados grupos de mestres que não obtivessem melhoria na renda. Dessa forma, o aumento de renda proveniente do mestrado, visto apenas com a abordagem de significância, poderia não ser suficiente para explicar essas ocorrências. Por isso procedeu-se também ao cálculo do coeficiente de variação que se dá dividindo-se o desvio-padrão das respostas pela média aritmética destas. Foram considerados altos todos os coeficientes de variação iguais ou superiores a $0,30(30 \%)$ por convenção, sempre com o intuito de possibilitar divisões em grupos a fim de dar maior riqueza e confiabilidade aos resultados, permitindo uma análise conjunta tanto quantitativa como qualitativa.

As divisões dos mestres por grupos de classificação também foram fundamentais para entender a relação causa-efeito de cada variável e suas inter-relações cruzadas, desde o pré-teste até a análise de dados.

Para se conhecerem todos os resultados e motivos das diferenças de rendas, são formulados subgrupos observando ocorrências nas respostas de questões sobre atuação na docência, superqualificação, vínculos empregatícios, quantidade de vínculos, e o envolvimento (ou não) de pesquisas científicas nas atividades remuneradas. A partir destes procedimentos de análise inicial, é proposta uma esquematização de divisão por grupos de resultados e também o cálculo do benefício financeiro apresentado na próxima seção.

\section{Apresentação e Análise dos Resultados}

Avaliações e percepções de características dos respondentes foram pesquisadas e analisadas.

A idade dos egressos, quando da conclusão do mestrado, é de 31,58 anos, em média (idade acima dos padrões internacionais). Este resultado corrobora os de Dickson e Smith (2011), que lembram a importância da variável de tempo disponível de serviço, com menor retorno financeiro, já que mestres com idade de formação tardia e com dois anos a mais de estudo teriam menor tempo disponível de serviço, após o mestrado, antes da aposentadoria ou do óbito.

Outra informação relevante é que apenas três mestres não possuem graduação em Contabilidade $(6,52 \%)$ e mesmo estes três possuem graduações próximas (administração). Esse resultado pode indicar a baixa interdisciplinaridade e mobilidade entre os cursos de diversas áreas. Um economista cursando mestrado em Contabilidade, por exemplo, teria o potencial de abrir um leque de oportunidades profissionais e de aprendizado.

A continuidade dos estudos dos respondentes após o curso também foi questionada e apresentou os resultados da Tabela 1 abaixo. 
Tabela 1

Continuidade dos estudos após o mestrado

\begin{tabular}{ccc}
\hline Tipo de curso/continuidade dos estudos & Total & $\%$ \\
\hline Doutorado em Contabilidade & 14 & $30,43 \%$ \\
\hline Doutorado em Administração & 4 & $8,70 \%$ \\
\hline Doutorado em Engenharia de Produção & 2 & $4,35 \%$ \\
\hline Especialização e/ou cursos em algum ramo da Contabilidade/Administração & 5 & $10,87 \%$ \\
\hline Especialização e/ou cursos em outras áreas & 3 & $6,52 \%$ \\
\hline Outros (minicursos de extensão, atualização) & 4 & $8,70 \%$ \\
\hline Nenhum curso & 14 & $30,43 \%$ \\
\hline Total Geral & 46 & $100,00 \%$ \\
\hline
\end{tabular}

Fonte: dados da pesquisa.

Os resultados da continuidade dos estudos após o mestrado são bem variados. Dos respondentes, $20(43,48 \%)$ cursam $(21,74 \%)$, ou cursaram doutorado (21,74\%). Dos mestres, 8 (17,39\%) dos mestres cursam, ou cursaram especializações e/ou outros cursos. Destes que cursaram especializações e outros cursos, 5 (10,87\%) responderam ter cursado mais de um curso, inclusive em outras áreas. Os demais 18 $(39,13 \%)$ ainda não deram continuidade aos estudos após o mestrado ou apenas se atualizaram e/ou fizeram minicursos de extensão.

Este resultado pode indicar o mestrado como último estágio educacional (longo) para boa parte dos mestres (26 que são 56,52\% do total), denotando suficiência no âmbito profissional e de realização/ satisfação pessoal, ambos reafirmados no levantamento de benefícios mais adiante. O fato de $43,48 \%$ estarem no estágio educacional de doutoramento não anula essa inferência, pois além de ser menos da metade, a maioria dos vínculos de docência do Brasil privilegia e, por vezes, até impõe o título de doutor para professores.

A atuação na docência, que é um dos principais objetivos do mestrado em Contabilidade da UFSC, também foi questionada. A Tabela 2 a seguir mostra os resultados dos 46 mestres.

Tabela 2

\section{Atuação ou não na docência (mestres)}

\begin{tabular}{ll}
\hline Características de atuação & Mestres \\
\hline Atuam na docência & $22(47,83 \%)$ \\
\hline Não atuam na docência & $24(52,17 \%)$ \\
\hline Atuavam na docência antes e/ou durante o mestrado & $19(41,30 \%)$ \\
\hline
\end{tabular}

Fonte: dados da pesquisa.

É importante esclarecer que 10 dos mestres respondentes estão cursando ainda o doutorado, sendo que apenas 2 destes lecionam. Mesmo assim, o percentual de mestres que atuam na docência é bastante baixo se comparado, por exemplo, aos resultados de Barth, Ensslin e Reina (2012), os quais registraram que de todos os mestres em Contabilidade da UFSC formados até 2009 (34 mestres), 27 exerciam docência, o que correspondia a 79,4\%. É uma queda bastante acentuada (35,92\% de queda). Porém não havia tantos doutorandos.

Os resultados de Dallabona et al. (2013) sugerem que 91,67\% dos mestres egressos do Programa de Pós-Graduação em Ciências Contábeis da Universidade Regional de Blumenau atuam na docência.

O baixo índice de atuação na docência do presente estudo $(47,83 \%)$ sugere que, em algum momento, após 2009, os mestres formados pela UFSC não conseguiram encontrar espaço no mercado para docência ou encontraram melhores oportunidades no mercado de trabalho (fora da docência). 
Assim, o mestrado em Contabilidade da UFSC não parece ser um diferencial que remeta o mestre para a docência. Corroborando esta afirmação, 19 dos 22 mestres que atuam na docência já a exerciam antes do mestrado. Essa característica não é, contudo, suficiente para determinar os benefícios ou validade do mestrado neste quesito, pois há diversos outros fatores a serem analisados que são expostos mais a frente.

Procurou-se conhecer as motivações que levaram os mestres ao curso. Foram pesquisadas as mesmas motivações propostas por Cunha et al. (2010). Também foi aberta a possibilidade para os respondentes citarem outros fatores. A Tabela 3 demonstra a importância de cada fator.

Tabela 3

Fatores da decisão por cursar o mestrado (mestres)

\begin{tabular}{lcc}
\hline Fatores na opção por cursar o mestrado & Não Pesou & Pesou \\
\hline Corrigir deficiências da graduação & $38(82,61 \%)$ & $8(17,39 \%)$ \\
\hline Seguir/aprimorar carreira docente & $8(17,39 \%)$ & $38(82,61 \%)$ \\
\hline Seguir/aprimorar carreira profissional & $7(15,22 \%)$ & $39(84,78 \%)$ \\
\hline Ampliar oportunidades de trabalho & $8(17,39 \%$ & $38(82,61 \%)$ \\
\hline Obter conhecimento aprofundado da Contabilidade & $9(19,57 \%)$ & $37(80,43 \%)$ \\
\hline Obter elevação de renda & $12(26,09 \%)$ & $34(73,91 \%)$ \\
\hline Obter diferenciação profissional & $2(4,35 \%)$ & $44(95,65 \%)$ \\
\hline Alcançar prestígio profissional/social & $6(13,04 \%)$ & $40(86,96 \%)$ \\
\hline Realização/Satisfação pessoal & $3(6,52 \%)$ & $43(93,48 \%)$ \\
\hline
\end{tabular}

Fonte: dados da pesquisa.

Todos os fatores motivacionais sugeridos obtiveram alta relevância na opção por cursar o mestrado, com exceção do primeiro (corrigir deficiências da graduação).

Martins e Monte (2010) pesquisaram fatores semelhantes, obtendo resultados mais modestos (peso relativamente inferior) para alguns fatores. O fator que mais pesou foi "obter mais conhecimento" $(88,54 \%)$. Ainda assim, todos os outros fatores obtiveram relevância para mais da metade dos mestres do Programa Multiinstitucional e Inter-Regional de Pós-Graduação em Ciências Contábeis da UnB/UFPB/ UFPE/UFRN. A exceção foi também o fator "corrigir deficiências da graduação", que teve peso de 46,67\%.

Dallabona et al. (2013) investigaram fatores semelhantes no Programa de Pós-Graduação em Ciências Contábeis da Universidade Regional de Blumenau. Embora os resultados tenham sido mensurados com abordagem diferente, os fatores que pesaram na opção por cursar o mestrado foram semelhantes. A exceção foi novamente o fator "corrigir deficiências da graduação" $(35,42 \%)$.

Na decisão por cursar, ou não, o mestrado, o fator financeiro obteve influência moderada já que a principal finalidade do mestrado, para estes (56,52\%), é de cunho mais social do que econômico. A intensidade do retorno, porém, é influenciadora da decisão pelo curso para os $43,48 \%$ restantes, porém apenas $8,70 \%$ esperam obter retorno financeiro considerável (entre $20 \%$ e $30 \%$ ).

Os vínculos empregatícios e fontes de renda são importantes para entender os resultados econômicos de forma precisa, sem provocar distorções de julgamento quanto aos retornos financeiros que realmente são, ou não, provenientes do mestrado.

Os mestres foram questionados a esse respeito. Dos respondentes, apenas $16(34,68 \%)$ possuíam, antes do mestrado, mais de um vínculo/fonte de renda. Os 30 demais $(65,22 \%)$ possuíam apenas um vínculo/fonte de renda. 
Quanto aos vínculos empregatícios/fontes de renda dos mestres após a titulação, os resultados demonstraram mudanças, conforme a Tabela 4 a seguir.

Tabela 4

Vínculos empregatícios ou fontes de renda posteriores ao mestrado

\begin{tabular}{lccc}
\hline \multirow{2}{*}{$\begin{array}{l}\text { Tipo de vínculo } \\
\text { empregatício }\end{array}$} & \multicolumn{3}{c}{ Após o mestrado } \\
\cline { 2 - 4 } & $\begin{array}{c}\text { Proveniente de (10) } \\
\text { mestres com múltiplos } \\
\text { vínculos }\end{array}$ & $\begin{array}{c}\text { Proveniente de (36) } \\
\text { mestres com apenas um } \\
\text { vínculo }\end{array}$ & $\begin{array}{c}\text { Total de vínculos } \\
\text { individuais e múltiplos } \\
\text { (46 mestres) }\end{array}$ \\
\hline Bolsista de doutorado & $2(10,00 \%)$ & $8(22,22 \%)$ & $10(17,86 \%)$ \\
\hline Dependente & $0(0 \%)$ & $0(0 \%)$ & $0(0 \%)$ \\
\hline Empregado setor privado & $4(20,00 \%)$ & $8(22,22 \%)$ & $12(21,43 \%)$ \\
\hline Empregado setor público & $14(70,00 \%)$ & $17(47,22 \%)$ & $31(55,36 \%)$ \\
\hline Proprietário ou sócio & $0(0 \%)$ & $3(8,34 \%)$ & $3(5,35 \%)$ \\
\hline $\begin{array}{l}\text { Autônomo, Consultor, } \\
\text { Liberal }\end{array}$ & $0(0 \%)$ & $0(0 \%)$ & $0(0 \%)$ \\
\hline Total & $\mathbf{2 0 ( 1 0 0 \% )}$ & $36(100 \%)$ & $\mathbf{5 6}(100 \%)$ \\
\hline
\end{tabular}

Fonte: dados da pesquisa.

A principal diferença nos vínculos empregatícios de antes para após o mestrado pode ser notada no setor público, em detrimento do setor privado. Houve aumento de $15,68 \%$, no setor público, e a diminuição de $13,49 \%$, no setor privado, são variações autos explicativas. Essas e outras variações são explicadas também pelo número de bolsistas de doutorado que por vezes, fazem com que os mestres se dediquem exclusivamente ao doutorado, deixando seus vínculos empregatícios.

Dallabona et al. (2013) encontraram 79,17\% de mestres egressos da Furb atuando na esfera privada. É um resultado bem diferente dos $21,43 \%$ atuantes no setor privado da presente pesquisa. Há uma aparente tendência: mestres egressos de instituição pública tendem a permanecer ou encontrar emprego no setor público. Enquanto que mestres egressos de instituição privada tendem a permanecer na esfera privada. Porém, os mestres daquele programa, como já visto, atuam fortemente na docência (91,67\%), enquanto que os mestres egressos da UFSC atuam na docência em uma proporção bastante inferior (47,83\%), o que pode ajudar a entender essas variações acentuadas nos vínculos empregatícios.

Os benefícios provenientes do mestrado foram pesquisados com base em Cunha (2007), que identificou os fatores que se alteram para o doutorado (com adição do fator realização pessoal sugerido por respondentes). Apresentaram-se então 20 fatores aos respondentes que, de acordo com o grau de relevância para cada item, deram nota de 1 a 10 para cada um. Os resultados estão evidenciados na Tabela 5 a seguir. 
Tabela 5

\section{Benefícios pessoais}

\begin{tabular}{|c|c|c|c|c|c|c|c|}
\hline Benefícios pessoais & Média & Mediana & Moda & DP & CV & Mín & Máx \\
\hline Realização/ Satisfação Pessoal & 8,93 & 10 & 9 & 1,25 & 0,14 & 5 & 10 \\
\hline Produção acadêmica & 8,70 & 10 & 9 & 1,46 & 0,17 & 4 & 10 \\
\hline Espírito acadêmico & 8,65 & 9 & 9 & 1,48 & 0,17 & 3 & 10 \\
\hline Amadurecimento pessoal & 8,52 & 9 & 9 & 1,66 & 0,19 & 3 & 10 \\
\hline Respeitabilidade e reconhecimento acadêmico/ profissional & 8,39 & 8 & 8,5 & 1,13 & 0,13 & 5 & 10 \\
\hline Diferenciação profissional & 8,35 & 8 & 8,5 & 1,54 & 0,18 & 2 & 10 \\
\hline Oportunidades na carreira & 8,26 & 10 & 9 & 1,78 & 0,22 & 2 & 10 \\
\hline Prestígio & 8,17 & 8 & 8 & 1,48 & 0,18 & 5 & 10 \\
\hline Competências analíticas & 8,04 & 8 & 8 & 1,63 & 0,20 & 2 & 10 \\
\hline Habilidade cognitiva & 8,02 & 9 & 8,5 & 1,73 & 0,22 & 2 & 10 \\
\hline Empregabilidade & 7,93 & 10 & 8 & 2,08 & 0,26 & 0 & 10 \\
\hline Status & 7,78 & 8 & 8 & 1,69 & 0,22 & 3 & 10 \\
\hline Mobilidade profissional & 7,74 & 8 & 8 & 1,98 & 0,26 & 0 & 10 \\
\hline Estilo de vida & 7,52 & 9 & 8 & 2,33 & 0,31 & 0 & 10 \\
\hline Autonomia profissional & 7,43 & 8 & 8 & 2,37 & 0,32 & 0 & 10 \\
\hline Produtividade & 7,37 & 9 & 8 & 2,30 & 0,31 & 0 & 10 \\
\hline Promoção social & 7,09 & 9 & 8 & 2,43 & 0,34 & 0 & 10 \\
\hline Responsabilidade social & 7,02 & 8 & 8 & 2,72 & 0,39 & 0 & 10 \\
\hline Remuneração & 6,39 & 8 & 7,5 & 2,79 & 0,44 & 0 & 10 \\
\hline Estabilidade profissional & 6,00 & 9 & 7 & 3,14 & 0,52 & 0 & 10 \\
\hline
\end{tabular}

Fonte: dados da pesquisa.

Observa-se que todos os fatores pesquisados tiveram avaliação positiva, embora os financeiros tenham tido menor relevância (estabilidade profissional, remuneração). Estes fatores obtiveram também os maiores coeficientes de variação entre todos os fatores pesquisados. Apesar de a avaliação de fatores econômicos ainda ser relativamente positiva, muitos demonstraram descontentamento, comprovado pelos altos desvios e médias bem moderadas.

Além disso, conforme explicitado mais a frente, foram poucos os respondentes que obtiveram mudanças significativas de renda e também poucos os que alcançaram a docência. Não se percebeu necessário apresentar tais resultados em grupos, pois estes resultados qualitativos são mais gerais do que específicos (de grupos), diferentemente do que ocorreu com resultados quantitativos que são abordados desta forma.

Martins e Monte (2010) pesquisaram esses mesmos fatores nos egressos do Programa Multiinstitucional e Inter-Regional de Pós-Graduação em Ciências Contábeis da UnB/UFPB/UFPE/UFRN. Os fatores que obtiveram maiores médias foram "amadurecimento profissional" $(8,30)$, "respeitabilidade e reconhecimento acadêmico/profissional" $(8,19)$, "espírito acadêmico" $(8,16)$ e "produção acadêmica" $(7,62)$. Já os fatores que obtiveram menor média naquele estudo são "remuneração" (6,02), "mobilidade profissional" $(5,87)$, "estilo de vida" $(5,44)$ e "estabilidade profissional" $(5,31)$. No geral, os resultados foram bastante próximos, já que naquele estudo o fator de realização/satisfação pessoal não foi pesquisado.

Dallabona et al. (2013) também pesquisaram os mesmos fatores para egressos do Programa de Pós-graduação em Ciências Contábeis da Universidade Regional de Blumenau. Seus resultados foram mensurados com outra abordagem, porém os fatores que mais se alteraram e os que menos se alteraram, em função do mestrado, também foram os mesmos de Martins e Monte (2010). 
Os mestres foram questionados também quanto à contribuição que o mestrado teve para com as atividades atuais dos mestres. Os itens propostos por Cunha (2007), para o doutorado, são os mesmos questionados nesta pesquisa para mestres e estão relacionados na Tabela 6 a seguir.

Tabela 6

Contribuições do mestrado para com as atividades atuais dos mestres

\begin{tabular}{lccc}
\hline Contribuições com Atividades Atuais dos Mestres & Nenhuma & Poucas & Muitas \\
\hline A formação teórica (básica ou aplicada) do mestrado & $1(2,17 \%)$ & $12(26,09 \%)$ & $33(71,74 \%)$ \\
\hline A experiência em pesquisa & $0(0 \%)$ & $6(13,04 \%)$ & $40(86,96 \%)$ \\
\hline A atualização dos conhecimentos em minha área & $2(4,35 \%)$ & $17(36,96 \%)$ & $27(58,69 \%)$ \\
\hline Contatos acadêmicos/ profissionais durante o curso & $1(2,17 \%)$ & $20(43,48 \%)$ & $25(54,35 \%)$ \\
\hline Desenvolvimento do pensamento crítico & $0(0 \%)$ & $5(10,87 \%)$ & $41(89,13 \%)$ \\
\hline Fonte: dados da pesquisa. & & &
\end{tabular}

As contribuições mais relevantes do mestrado para com as atividades atuais dos respondentes são "desenvolvimento do pensamento crítico", "a experiência em pesquisa" e a "formação teórica". As menos significativas, apesar de relevantes, são "contatos acadêmicos / profissionais durante o mestrado" e a "atualização dos conhecimentos em minha área”.

Cunha, Cornachione Junior e Martins (2010) pesquisaram essas mesmas contribuições para com atividades atuais, mas para o nível de doutorado. Todas também foram relevantes, porém a mais significativa foi a "formação teórica" e a menos significativa foi "contatos acadêmicos/profissionais durante o curso".

Para se conhecerem os benefícios financeiros possíveis, do mestrado, procurou-se evitar distorções advindas de outras variáveis como rendas anteriores (inflação, aumentos do salário mínimo anual) e motivos das variações de renda como o fato de alguns mestres possuírem também o doutorado. A possibilidade de superqualificação também foi observada de acordo com os estudos de Barth et al. 2015, e seus resultados foram utilizados para as subdivisões de grupos aqui abordadas. sultados:

Primeiramente, optou-se por dar uma visão geral das rendas da amostra, obtendo os seguintes re-

Tabela 7

Visão geral da renda dos mestres em diferentes períodos (em salários mínimos)

\begin{tabular}{cccc}
\hline Procedimento estatístico & $\begin{array}{c}\text { Renda geral } \\
\text { anterior ao mestrado }\end{array}$ & $\begin{array}{c}\text { Renda geral } \\
\text { durante o mestrado }\end{array}$ & $\begin{array}{c}\text { Renda geral } \\
\text { após o mestrado }\end{array}$ \\
\hline Média & 6,39 & 5,72 & 9,59 \\
\hline Moda & 3 & 2 & 3 \\
\hline Mediana & 5 & 3 & 7,5 \\
\hline Desvio-Padrão & 4,70 & 5,08 & 6,74 \\
\hline C.V. & 0,74 & 0,89 & 0,70 \\
\hline Mínimo & 1 & 2 & 3 \\
\hline Máximo & 25 & 25 & 28 \\
\hline
\end{tabular}

Fonte: dados da pesquisa.

O coeficiente de correlação de Pearson entre a renda geral anterior e posterior foi de 0,82 , mostrando que existe dependência positiva entre os valores de rendas anteriores e posteriores. Em outras palavras, quanto maiores as rendas anteriores, maiores são as chances de a renda posterior ser também elevada. 
Houve um aumento de mais de três salários mínimos na renda geral, após o mestrado, quando comparada com a renda anterior ao mestrado. Com intervalo de confiança de 90\%, o t-crítico foi de $\pm 1,68$. Assim, pode-se afirmar que a renda aumentou após o mestrado, o que não quer dizer que aumentou por causa do mestrado, e nem para a maioria dos respondentes.

Como se pode perceber, há heterogeneidade alta nas rendas e em todas as variações, tornando necessárias explicações mais profundas e divididas por grupos, a fim de conhecer os motivos das variações.

Outra inferência que se pode fazer é que houve uma queda das rendas durante o mestrado (devido ao valor da bolsa de dedicação exclusiva).

Em termos de aumento de renda, independente de serem pequenos ou altos, foi exatamente 30 $(65,22 \%)$ o número de mestres que obtiveram algum aumento.

A variação entre renda anterior e posterior ao curso foi de exatamente 50\%. Diversos estudos já apontados no referencial teórico entendem esse tipo de variação como "retorno financeiro". Para efeito comparativo entre programas, regiões e países, foram destacadas algumas dessas variações.

Coates e Edwards (2011) concluíram que na Austrália as variações entre as rendas anteriores e posteriores para pós-graduados são de $58 \%$, em média.

Martins e Monte (2009a) verificaram que houve uma variação entre renda anterior e posterior de 88,68\% para mestres egressos do Programa Multi-institucional e Inter-Regional de Pós-Graduação em Ciências Contábeis da UnB/UFPB/UFPE/UFRN.

De acordo com o CGEE (2013), brasileiros, cujo nível de instrução mais elevado é o mestrado, recebem remuneração média $84 \%$ superior aos que apenas concluíram o curso superior.

Estes estudos não levaram em consideração variações advindas do tempo e de outras variáveis (mudanças salariais, inflação, tipo de atividade, superqualificação, tipo de vínculo, outros cursos). Essas distorções são por vezes graves alterando completamente o entendimento dos resultados. Além disso, médias salariais gerais não informam a proporção de mestres que obteveram mudança salarial significativa.

Dallabona et al. (2013) verificaram que, dos 48 mestres egressos do mestrado da Furb, aproximadamente $50 \%$ obtiveram mudanças significativas, auferindo rendas superiores a 9 salários mínimos. É um resultado bastante próximo do obtido na presente pesquisa (nas médias salariais gerais), porém não foi calculada a significância daqueles resultados, nem houve divisão por grupos para entender as variações acentuadas. O mesmo ocorreu com os outros estudos citados.

Pela estatística t, no intervalo de confiança de $90 \%$, os aumentos de renda considerados significantes, para o presente estudo, são as variações de pelo menos dois salários mínimos. Assim, apenas 20 (43,48\%) mestres respondentes obtiveram aumentos significativos até o momento.

Outra possível abordagem quanto a serem significativos, os aumentos de renda, nos diferentes períodos, é a variação por estratos sociais (segundo o IBGE), exposta a seguir:

Tabela 8

Visão geral da renda em diferentes períodos (segundo classificação do IBGE por estratos sociais)

\begin{tabular}{ccccccc}
\hline Classe & E & D & C & B & A & Total \\
\cline { 1 - 5 } Renda mensal & De 0 a 2 & Mais de 2 até 4 & Mais de 4 até 10 & Mais de 10 até 20 & Mais de 20 & \\
\hline Anterior ao mestrado & $4(8,70 \%)$ & $16(34,78 \%)$ & $18(39,13 \%)$ & $7(15,22 \%)$ & $1(2,17 \%)$ & $46(100 \%)$ \\
\hline Durante o mestrado & $22(47,83 \%)$ & $2(4,35 \%)$ & $14(30,43 \%)$ & $7(15,22 \%)$ & $1(2,17 \%)$ & $46(100 \%)$ \\
\hline Após o mestrado & $0(0,00 \%)$ & $12(26,09 \%)$ & $18(39,13 \%)$ & $10(21,74 \%)$ & $6(13,04)$ & $46(100 \%)$ \\
\hline
\end{tabular}

Fonte: dados da pesquisa. 
Aqui fica evidente que a queda nas rendas durante o mestrado se deve, principalmente, em função do baixo valor das bolsas de dedicação exclusiva. Após o mestrado, nenhum mestre respondente pertence mais a classe $\mathrm{E}$ (até $\mathrm{R} \$ 1.448$ ); houve também diminuição de $8,69 \%$ na classe $\mathrm{D}$; a classe $\mathrm{C}$ permanece inalterada; a classe B aumentou em 6,52\%; a maior alteração se deu na classe A, que subiu 10,87\% após o mestrado. O número de mestres que obtiveram mudanças positivas significativas (com mudança de classe social) foi de apenas $20(43,48 \%)$. As duas abordagens (IBGE e teste $t$ ), coincidentemente, obtiveram 20 mestres respondentes com mudanças na renda positivas.

Olhando as rendas apenas no geral, não há como afirmar a viabilidade financeira do mestrado nem mesmo para os que obtiveram aumento significativo de renda. Esse problema já foi abordado na seção de métodos da pesquisa. Logo, os agrupamentos por características também qualitativas se fazem necessários, devido aos altos coeficientes de variação desses resultados e inter-relações cruzadas. Essa abordagem é apresentada adiante.

Os resultados quantitativos, pertinentes ao estudo, cujo coeficiente de variação foi considerado alto (maior que 0,30) foram: a) renda de docência/pesquisa anterior ao mestrado; b) renda de docência/pesquisa posterior ao mestrado; c) renda geral posterior ao mestrado; e d) renda geral anterior ao mestrado.

Os coeficientes de variação de renda proveniente da docência calculados foram de 0,52 , para renda posterior de docência, e 0,71 , para renda anterior de docência. A renda proveniente de docência posterior ao mestrado, na qual o coeficiente de variação foi de 0,52 , os grupos possíveis foram: a) renda principal é proveniente de vínculo em docência/pesquisa, mas não possui doutorado; b) renda principal é proveniente de vínculo em docência/pesquisa, mas possui doutorado; c) renda secundária (apenas complementar) é proveniente de vínculo em docência/pesquisa. Não há mestres com doutorado que atuem na docência de forma secundária (apenas complementar na renda).

Essas divisões servem para aproximar por grupos as distâncias entre as respostas, que, por consequência, diminuem o coeficiente de variação, possibilitando melhor qualidade nos resultados que são apresentados em função das melhores aproximações por grupos possíveis.

Após a divisão por grupos, o coeficiente de variação foi recalculado (a fim de justificar ou validar as divisões) obtendo-se o valor de 0,20, para o grupo a); 0,31, para o grupo b); e 0,37, para o grupo c). Apesar de os grupos b) e c) ainda terem variação considerável, não se procedeu a uma nova divisão, pois, caso fosse separado por setores de atuação por exemplo, público ou privado, o coeficiente não apresentaria diminuição (o que significa a não possibilidade de afirmar diferenças de renda entre setores de atuação para esses grupos).

Já para renda anterior de docência/pesquisa, investigaram-se também respostas qualitativas de correlação elevada. Elencaram-se possíveis motivos do alto coeficiente de variação expostos na seguinte divisão por grupos: a) renda era proveniente de múltiplos vínculos; b) renda era proveniente de apenas um vínculo (docência).

Após a divisão por grupos, o coeficiente de variação, que era de 0,71 , foi recalculado, obtendo-se o valor de 0,31 para o grupo a) e 0,27 para o grupo b).

Devido às características de um mestrado stricto sensu, no qual os principais objetivos são formar docentes e pesquisadores, questionou-se aos mestres sobre suas rendas provenientes da docência/pesquisa. Os resultados foram divididos por grupos. Os resultados das rendas anteriores ao mestrado provenientes da docência/pesquisa estão a seguir. 
Tabela 9

Rendas provenientes da docência/pesquisa antes do mestrado (em salários mínimos)

\begin{tabular}{lcc}
\hline Procedimento estatístico & $\begin{array}{c}\text { Renda era proveniente de } \\
\text { apenas um vínculo } \\
\text { (docência/pesquisa) }\end{array}$ & $\begin{array}{c}\text { Renda era proveniente de } \\
\text { múltiplos vínculos (docência/ } \\
\text { pesquisa e complementar) }\end{array}$ \\
\hline Média & 6,13 & 1,73 \\
\hline Moda & 5 & 2 \\
\hline Mediana & 6 & 2 \\
\hline Desvio Padrão & 1,89 & 0,47 \\
\hline C.V. & 0,31 & 0,27 \\
\hline Mínimo & 4 & 1 \\
\hline Máximo & 9 & 2 \\
\hline Número de respondentes que se enquadram & 8 & 11 \\
\hline
\end{tabular}

Fonte: dados da pesquisa.

A principal diferença na renda proveniente da docência/pesquisa antes do mestrado é a quantidade de atividades remuneradas (vínculos). Demais variações são explicadas pela carga horária, já que não foram identificadas variações significativas entre os setores de atuação (público ou privado).

As rendas provenientes da docência/pesquisa após o mestrado estão expostas a seguir:

Tabela 10

Renda proveniente da docência/pesquisa após o mestrado (em salários mínimos)

\begin{tabular}{lccc}
\hline Procedimento estatístico & $\begin{array}{c}\text { Renda principal é } \\
\text { proveniente de vínculo } \\
\text { em docência/pesquisa, } \\
\text { mas POSSUl doutorado }\end{array}$ & $\begin{array}{c}\text { Renda principal é } \\
\text { proveniente de vínculo em } \\
\text { docência/pesquisa, mas } \\
\text { NÃo possui doutorado }\end{array}$ & $\begin{array}{c}\text { Renda secundária } \\
\text { (apenas complementar) } \\
\text { é proveniente de vínculo } \\
\text { em docência pesquisa }\end{array}$ \\
\hline Média & 9,75 & 7,43 & 2,86 \\
\hline Moda & 8 & 8 & 2 \\
\hline Mediana & 10 & 8 & 2 \\
\hline Desvio-Padrão & 3,06 & 1,51 & 1,07 \\
\hline C.V. & 0,31 & 0,20 & 0,37 \\
\hline Mínimo & 6 & 6 & 2 \\
\hline Máximo & 13 & 10 & 4 \\
\hline Número de respondentes & 8 & 7 & 7 \\
que se enquadram & & & \\
\hline
\end{tabular}

Fonte. dados da pesquisa.

As rendas dos docentes/pesquisadores após o mestrado variam principalmente em função do título de doutorado e o fato de a docência/pesquisa ser, ou não, a atividade remunerada principal. É importante explicar que nenhum dos mestres que atuam na docência, de forma secundária (complementar), possui doutorado. Outra informação relevante é que não foi identificada variação salarial significativa de docentes/pesquisadores entre setores de atuação (público ou privado).

Comparando os resultados de principal atividade remunerada com o Programa Multiinstitucional e Inter-Regional de Pós-Graduação em Ciências Contábeis da UnB/UFPB/UFPE/UFRN, tem-se o estudo de Martins e Monte (2009b). Os mestres egressos daquele estudo tinham suas atividades remuneradas principais vinculadas ao mercado $(67,44 \%)$. Já na presente pesquisa, $31(67,39 \%)$ dos mestres têm sua principal atividade também no mercado e, não, na docência, o que é um resultado bastante próximo. 
Conforme proposto na seção de métodos da pesquisa, os mestres são separados em grupos com a finalidade de se conhecer em quais situações o mestrado traz benefícios financeiros. Assim, os grupos apresentam as divisões e resultados conforme a Figura 1.

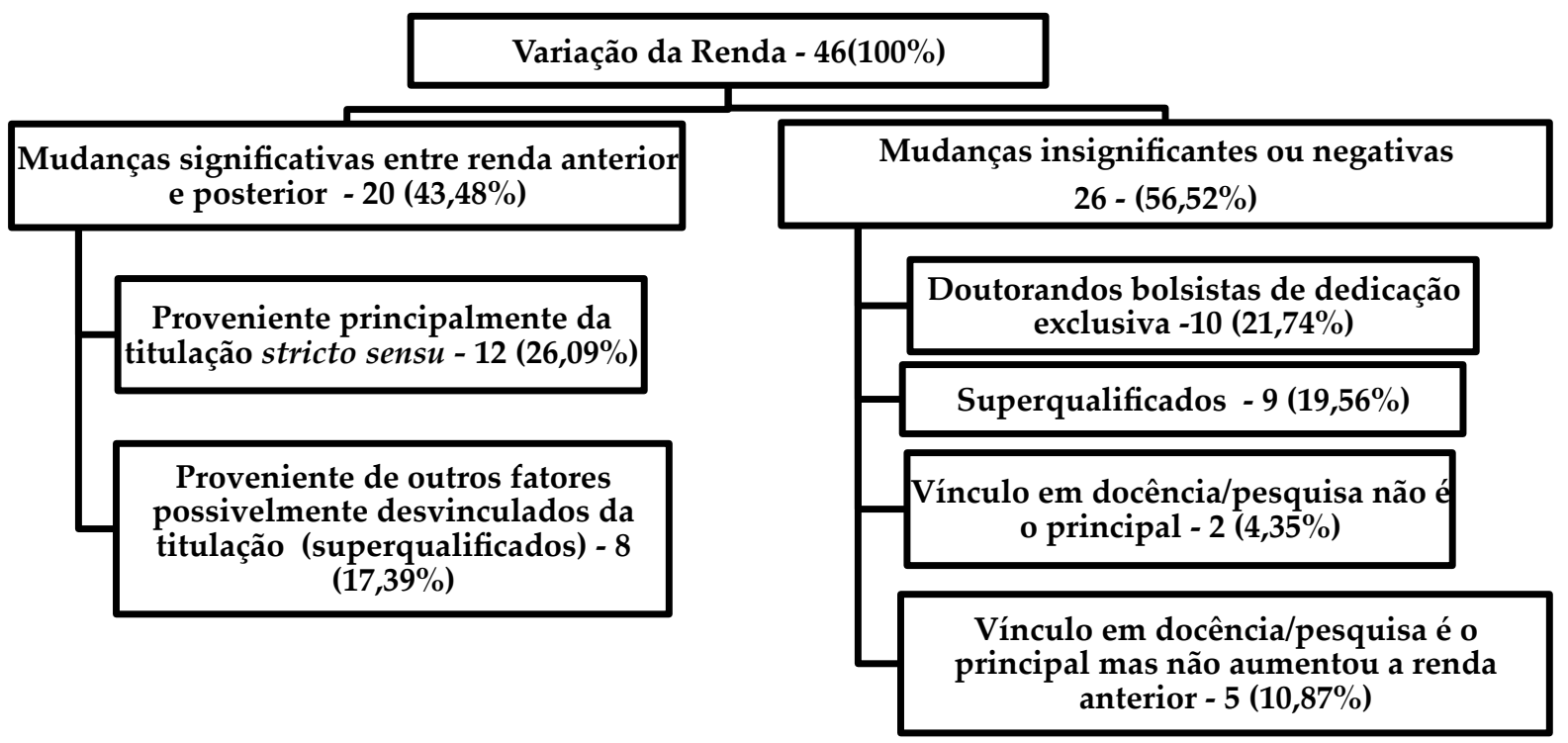

Figura 1. Organograma das variações de renda com resultados dos respondentes por grupos Fonte: dados da pesquisa.

Menos da metade dos respondentes (43,48\%) alcançou sucesso financeiro por cursar o mestrado, pelo menos momentaneamente. Dos respondentes, 19 se consideram superqualificados (qualificação maior que a exigida para função que desempenham), sendo que 10 são do grupo que obteve mudanças significativas de renda, conforme a subdivisão a seguir.

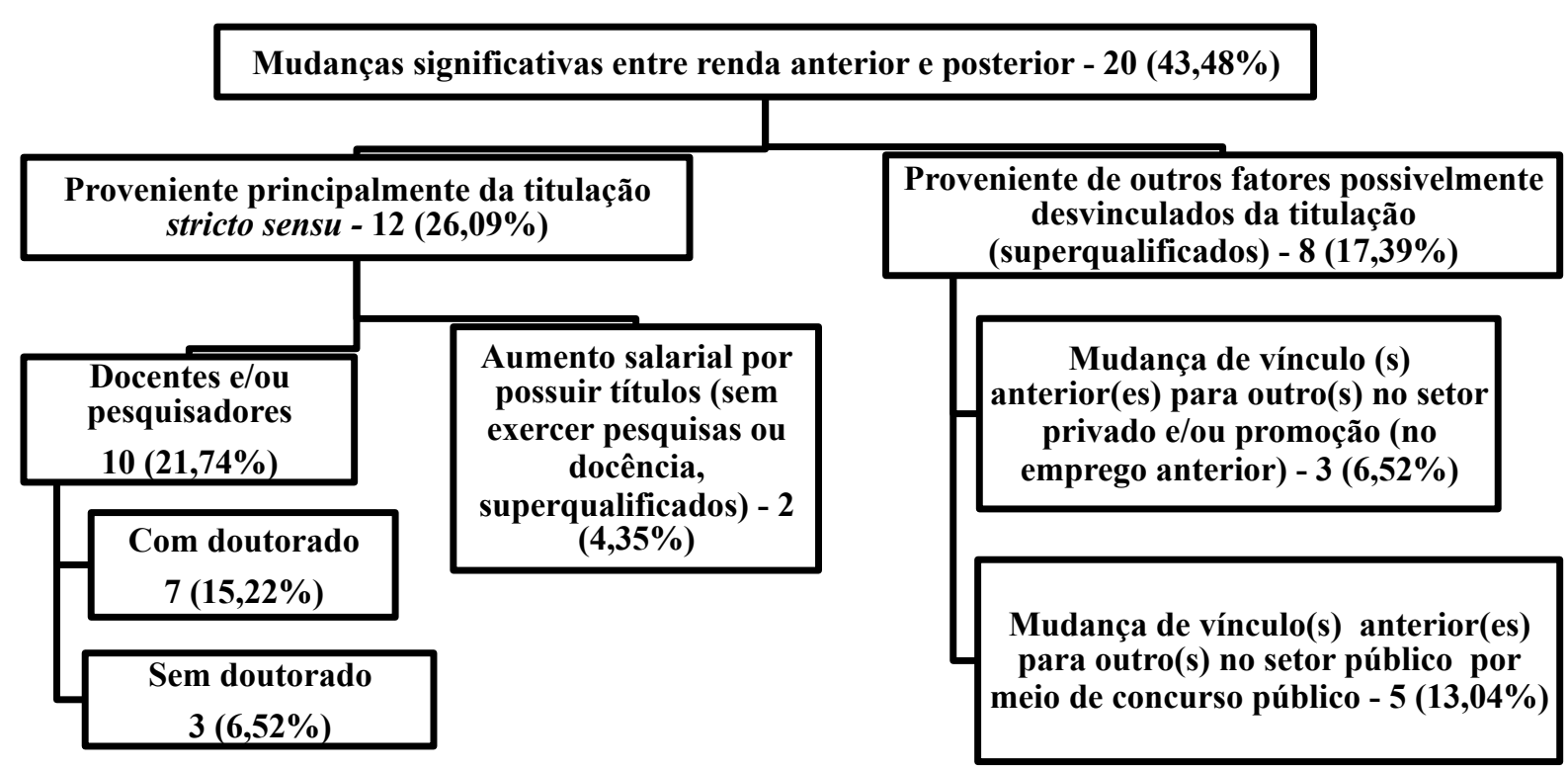

Figura 2. Organograma de subdivisões de grupos de mudança significativa na renda

Fonte: dados da pesquisa. 
Entretanto, é importante frisar que $3(6,52 \%)$ dos que obtiveram mudanças salariais desvinculadas da titulação atuam na docência de forma secundária (remuneração docente irrisória), ou seja, seus principais vínculos e fontes de renda não são da docência/pesquisa (lecionam apenas uma ou duas aulas). De fato estes podem considerar-se superqualificados, pois, apesar de quererem atuar na docência, não a alcançaram de forma satisfatória.

Ressalta-se que esta é uma percepção dos próprios respondentes (que se consideraram superqualificados), não sendo arbitrária, apesar de se concordar com esses três respondentes quanto a sua suposta superqualificação. Possíveis motivos para esta ocorrência podem ser tanto a falta de oportunidade quanto o salário inferior da docência em relação à remuneração de outras atividades desses respondentes.

Há 8 respondentes que possuem doutorado completo e que atuam na docência, porém, como mostrado na figura 2, há 7 deles que alcançaram melhoria significativa na renda por conta da docência/pesquisa. Existem 7 mestres que não possuem doutorado, mas que atuam na docência, apenas 3 alcançaram melhoria significativa na renda. Esses resultados sugerem melhores oportunidades para quem cursou também o doutorado.

Esse resultado também sugere que os 10 bolsistas de doutorado tendem a alcançar melhores oportunidades e rendas quando finalizarem o curso. Explicando, em outras palavras, 21,74\% (bolsistas de doutorado) dos 46 mestres tendem a ter sua situação de renda alterada significativamente, migrando do grupo de mudanças insignificantes de renda para o grupo de mudanças significantes na renda, em breve. Apenas um doutor não está atuando na docência/pesquisa, porém possui renda elevada no setor público.

Os benefícios financeiros são afetados principalmente pelas diferenças entre rendas anteriores e posteriores ao mestrado com parâmetros explanados nos métodos da pesquisa.

Os benefícios financeiros podem ser calculados conforme a equação (1):

$$
Z_{i}=\beta_{1} X_{1}-\beta_{2} X_{2}+\varepsilon_{i}
$$

A estimação dos parâmetros depende da média de cada grupo. A unidade de medida de todas as variáveis está também em salários mínimos. A média da variável de renda anterior ao mestrado do grupo que obteve mudanças significativas entre renda anterior e posterior é de 5,90 salários mínimos. Já a renda posterior ao mestrado deste mesmo grupo é de 12,55 salários mínimos. Assim, o valor médio dos benefícios $(Z)$ pode ser calculado:

$$
\begin{gathered}
Z=12,55-5,90+\varepsilon \\
Z=6,65+\varepsilon
\end{gathered}
$$

Porém, estimando os parâmetros $\beta$ para cada subgrupo de resultados, os valores dos benefícios financeiros $(Z)$ são distintos.

Na situação $1\left(Z_{1}\right)$ tem-se o subgrupo "Docentes e/ou pesquisadores com doutorado".

$$
\begin{gathered}
Z_{1}=\beta_{3} X_{3}-\beta_{4} X_{4}+\varepsilon_{1} \\
Z_{1}=0,91 \times 12,55-0,92 \times 5,90+\varepsilon_{1} \\
Z_{1}=5,99+\varepsilon_{1}
\end{gathered}
$$

Observa-se que os coeficientes informam o quanto cada situação fez as rendas variarem em relação à média geral.

Os benefícios financeiros para a situação 1 foram de 5,99 salários mínimos mensais, aproximadamente. Os mestres que se enquadram nessa situação são 7 (15,22 \%). 
A situação $2\left(Z_{2}\right)$ avalia o subgrupo "Docentes e/ou pesquisadores sem doutorado".

$$
\begin{gathered}
Z_{2}=0,64 \times 12,55-0,73 \times 5,90+\varepsilon_{2} \\
Z_{2}=3,72+\varepsilon_{2}
\end{gathered}
$$

Os benefícios financeiros na situação 2 são de 3,72 salários mínimos mensais aproximadamente. Os mestres que se enquadram nessa situação são 3 (6,52\%).

A situação $3\left(Z_{3}\right)$ observa o subgrupo "Aumento salarial por possuir títulos (sem exercer pesquisas ou docência, superqualificados)"

$$
\begin{gathered}
Z_{3}=1,08 \times 12,55-1,44 \times 5,90+\varepsilon_{3} \\
Z_{3}=5,06+\varepsilon_{3}
\end{gathered}
$$

Assim, tem-se que na situação 3 os benefícios financeiros são de 5,06 salários mínimos mensais, aproximadamente. Os mestres que se enquadram nessa situação são apenas $2(4,35 \%)$.

As situações 4 e 5 avaliam o grupo de mestres que obteve mudanças salariais proveniente de outros fatores possivelmente desvinculados da titulação. Contudo, devido a incerteza já mencionada, também efetua-se o cálculo para interessados que possam se enquadrar nesses subgrupos.

A situação $4\left(Z_{4}\right)$ analisa o subgrupo "Mudança de vínculo(s) anterior(es) para outro(s) no setor privado e/ou promoção (no emprego anterior).

$$
\begin{gathered}
Z_{4}=1,38 \times 12,55-1,30 \times 5,90+\varepsilon_{4} \\
Z_{4}=9,65+\varepsilon_{4}
\end{gathered}
$$

Para a situação 4 os benefícios financeiros são de 9,65 salários mínimos mensais, aproximadamente. Os mestres que se enquadram nessa situação são 3 (6,52\%).

Há ainda a situação $5\left(Z_{5}\right)$ na qual se observa o subgrupo "Mudança de vínculo(s) anterior(es) para outro(s) no setor público por meio de concurso público".

$$
\begin{gathered}
Z_{5}=1,08 \times 12,55-0,92 \times 5,90+\varepsilon_{5} \\
Z_{5}=8,13+\varepsilon_{5}
\end{gathered}
$$

A situação 5 demonstra benefícios financeiros próximos de 8,13 salários mínimos mensais. Os mestres que se enquadram nessa situação são 5 (13,04\%).

A fim de contemplar o resultado dos benefícios financeiros de todos os mestres, elenca-se ainda a situação 6. Nesta situação encontram-se todos os demais mestres respondentes que não obtiveram mudanças significativas na renda. Nestes casos, a renda anterior teve média de 6,77 enquanto que a renda posterior teve média de 7,31 .

$$
\begin{gathered}
Z_{6}=7,31-6,77+\varepsilon_{6} \\
Z_{6}=0,54+\varepsilon_{6}
\end{gathered}
$$

A situação 6 demonstra que não houve benefícios financeiros para este grupo, já que rendas anteriores e posteriores não obtiveram variação significativa (aproximadamente 0,54 salários mínimos mensais). Os respondentes que se enquadram nessa situação são 26 (56,52\%). Porém, é importante deixar claro que $10(21,74 \%$ do total $)$ mestres respondentes são ainda bolsistas de doutorado. Estes bolsistas tendem a ser pertencentes, principalmente, à situação 1, quando terminarem o doutorado. 
O Gráfico 1 a seguir apresenta um resumo informativo das situações de benefícios financeiros abordadas.

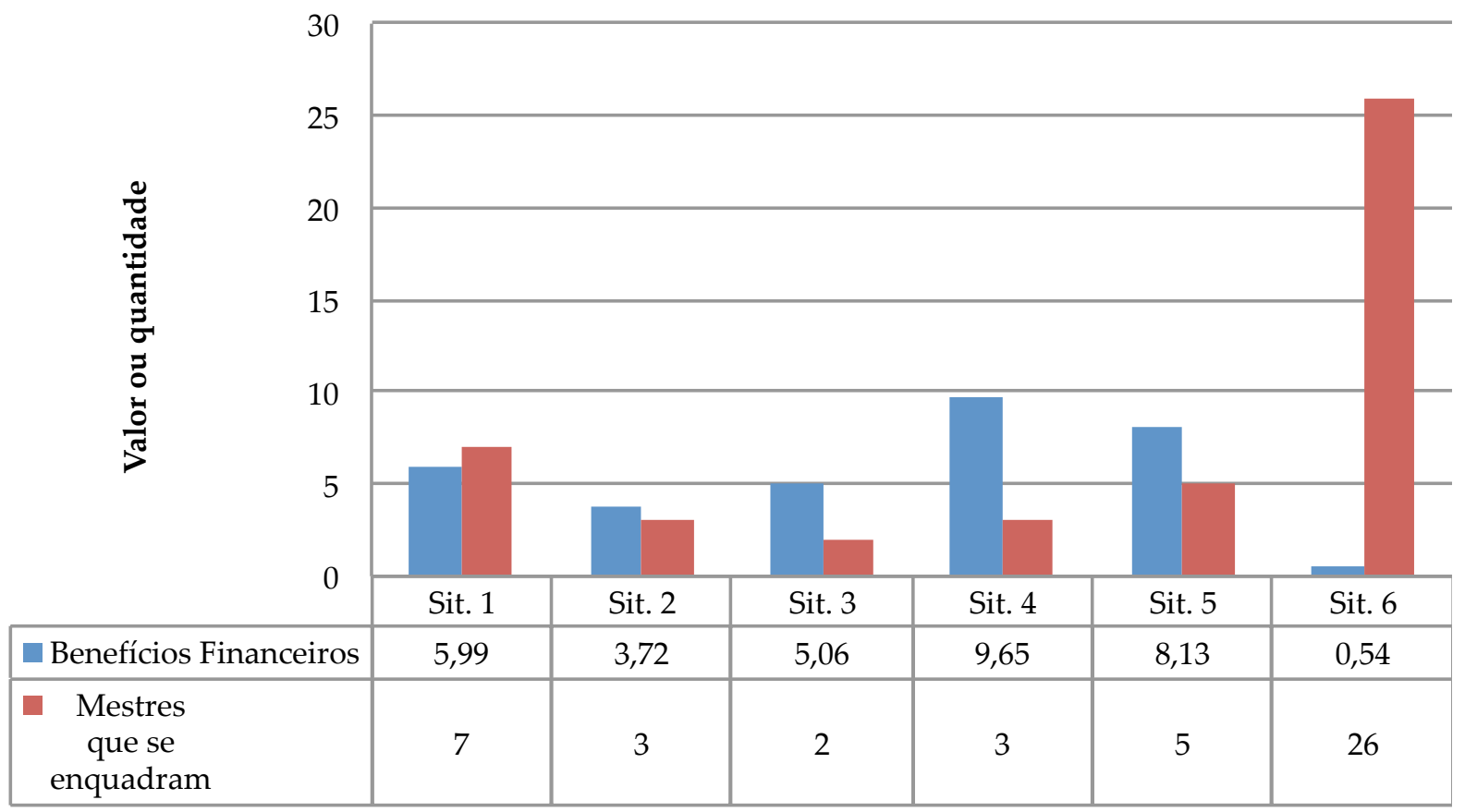

Gráfico 1. Situações de benefícios financeiros no mestrado

Fonte: dados da pesquisa.

Pelo Gráfico 1 é nítido que a situação 6 tem maior peso (56,52\%), seguida pelas situações 1 e 5 . Porém, se excluirmos os bolsistas de doutorado esse peso seria equivalente a 34,78\%. Dado os pesos diferenciados em relação ao número de respondentes que se enquadram em cada situação, optou-se por calcular a média ponderada:

$$
\begin{gathered}
M_{p}=\frac{5,99 \times 7+3,72 \times 3+5,06 \times 2+9,65 \times 3+8,13 \times 5+0,54 \times 26}{7+3+2+3+5+26} \\
M_{p}=3,19 \mathrm{sm}
\end{gathered}
$$

Assim, apenas para dar uma visão geral, tem-se que o mestrado possui um benefício financeiro médio ponderado de 3,19 salários mínimos mensais.

Como a idade média de titulação estimada é de 31,57 anos, o tempo estimado para usufruir destes benefícios é de 33,43 anos (tempo de força de trabalho ou contribuição, antes da idade média de aposentadoria). Assim, o mestrado proporciona um benefício financeiro de 1.279,70 salários mínimos ao longo da carreira, em média. Porém, os interessados devem efetuar o cálculo de acordo com as situações as quais se enquadram para evitar distorções, já que a maioria não obteve benefícios financeiros, pelo menos momentaneamente.

Com intervalo de confiança de $90 \%(\alpha=0,1)$, o $t$-crítico é de 1,68 , como as respostas são valores inteiros, são consideradas as variações de pelo menos 2 salários mínimos. Assim, podemos testar a hipótese: Esta amostra do mestrado em Contabilidade corrobora ou com a Teoria do Capital Humano. Nesse caso, apenas 20 (43,48\%) mestres respondentes estão acima da região crítica. Ou seja, 56,52\% dos respondentes não estão em conformidade com a Teoria do Capital Humano.

Outra abordagem é a de divisão por grupos. Nesse caso, apenas 12 (26,09\%) mestres respondentes estão acima da região crítica, levando em conta evidências de que foi a titulação que aumentou a renda. 
Em ambas as abordagens, fica rejeitada a hipótese nula (prova Teoria do Capital Humano), já que mais da metade dos mestres não alcançaram aumento de renda, tanto em função da titulação quanto por qualquer outro motivo.

No entanto, como já discutido, 10 mestres estão ainda cursando o doutorado com bolsas. Para aprofundar a análise, podem-se reavaliar as hipóteses transferindo esse grupo de bolsistas para o grupo "Mudanças significativas" no subgrupo "Proveniente principalmente da titulação stricto sensu". Nesse caso, 22 (47,83\%) estariam acima da região crítica. Assim, de qualquer modo, fica rejeitada a hipótese nula, pois a maioria dos mestres respondentes não obteve aumento significativo de renda em função da titulação.

Analisando as hipóteses por características (agrupamentos), o mestrado gerou retorno financeiro, de acordo com a Teoria do Capital Humano, apenas em três circunstâncias: a) mestres que possuem também o doutorado; b) mestres com cargos públicos que remuneram mais por possuir títulos; e c) mestres que auferiam rendas baixas antes do mestrado e hoje atuam somente na docência. Todos os demais agrupamentos rejeitam a hipótese nula, pelo menos momentaneamente.

Embora as abordagens sejam distintas, para efeito de comparação, observamos o estudo de Lordêlo e Verhine (2001). Os resultados daquele estudo demonstraram que os cursos são ótimas opções de investimento, com exceção exclusivamente dos profissionais que têm dedicação parcial às instituições e múltiplos vínculos empregatícios que implicam em alta renda sacrificada ao se optar pelos cursos. De fato todos que se enquadram nessa situação não obtiveram retorno financeiro para a presente pesquisa, corroborando parte dos resultados destes autores. Porém, na presente pesquisa, houve diversas outras situações às quais não foi possível obter benefícios financeiros significativos com o mestrado. Estas não foram abordadas por aquele estudo e nem pelos outros estudos identificados.

\section{Conclusão}

O objetivo deste trabalho foi avaliar o benefício da pós-graduação stricto sensu, no âmbito pessoal, segundo a percepção de seus egressos. Essa pesquisa contribuiu com percepções a respeito da Teoria do Capital Humano e da economia da educação no âmbito da pós-graduação. Também contribuiu para a tomada de decisão por parte dos usuários da pós-graduação em Contabilidade, do ponto de vista pessoal, sem deixar de lado as individualidades e variações advindas de outros fatores não relacionados ao curso.

As expectativas dos respondentes, para o mestrado eram alcançar realização/satisfação pessoal, obter conhecimento aprofundado da Contabilidade, seguir/aprimorar carreira profissional e docente, obter diferenciação profissional, ampliar oportunidades de trabalho, elevar renda e conquistar prestígio profissional/social.

Todos os 20 possíveis benefícios pessoais advindos da titulação foram avaliados positivamente pelos mestres respondentes. Os principais benefícios, em ordem decrescente de relevância, foram realização/ satisfação pessoal; produção acadêmica; espírito acadêmico; amadurecimento pessoal; respeitabilidade e reconhecimento acadêmico/profissional; diferenciação profissional; oportunidades na carreira; prestígio; competências analíticas; habilidade cognitiva; empregabilidade; status; mobilidade profissional; estilo de vida; autonomia profissional; produtividade; promoção social; responsabilidade social; remuneração; estabilidade profissional. Na visão dos respondentes, o mestrado ofereceu/desenvolveu fatores importantes para com suas atividades atuais como, formação teórica (básica e aplicada); experiência em pesquisa; pensamento crítico; atualização dos conhecimentos na área; e contatos acadêmicos ou profissionais.

O curso mostra-se como boa opção, já que atendeu às expectativas em relação aos fatores analisados para a maioria dos respondentes.

Os benefícios financeiros, por outro lado, não foram alcançados satisfatoriamente para a maioria dos mestres (56,52\%). Houve 6 situações de benefícios financeiros após o mestrado que variaram de 0,54 até 9,65 salários mínimos mensais, com média ponderada de 3,19 salários mínimos mensais. Como a idade média de titulação estimada é de 31,57 anos, o tempo estimado para usufruir destes benefícios é de 33,43 
anos (tempo de força de trabalho ou contribuição). Assim, o mestrado proporciona um benefício financeiro de 1.279,70 salários mínimos ao longo da carreira, em média. Levando-se em conta evidências de que foi a titulação que aumentou a renda, apenas $26,09 \%$ alcançaram êxito financeiro advindo do curso, os demais aumentos podem ser exógenos à pós-graduação.

O mestrado gerou benefício financeiro efetivo apenas para três grupos de respondentes: mestres que possuem também o doutorado; mestres com cargos públicos que remuneram mais por possuir títulos; e mestres que auferiam rendas baixas antes do mestrado e hoje atuam somente na docência. Todos os demais agrupamentos elencados não obtiveram benefícios financeiros significativos. Apesar disso, nenhum mestre respondente está desempregado ou auferindo renda inferior a três salários mínimos, corroborando a conclusão de Menon et al. (2012), em que graduados que completaram a pós-graduação possuem uma melhor chance de encontrar emprego depois da formatura do que os outros. Apesar disso, essa afirmativa não pode ser comprovada, pois o presente estudo não foi feito com graduados em Contabilidade, somente com mestres.

Os resultados não foram aderentes à Teoria do Capital Humano, pelo menos para 56,52\% dos mestres. Para o grau de mestre, anos a mais de educação não geraram resultados econômicos para esse percentual de respondentes. Porém, quando aliado ao doutoramento, foi, em todos os casos observados, confirmada a concepção de que a educação (mesmo em seus graus mais elevados) aumenta a renda dos indivíduos significativamente.

O mestrado acadêmico em Contabilidade, objeto deste estudo, revelou-se viável do ponto de vista pessoal dos respondentes. Porém, em se tratando de finanças não, salvo se acompanhado da titulação de doutor. Há, porém, outros casos específicos de viabilidade financeira, embora escassos e menos prováveis $(10,87 \%)$ já mencionados.

Como sugestões para outras pesquisas, propõem-se que sejam pesquisados os benefícios da graduação, de outras pós-graduações e também do doutorado em Contabilidade com base em fatores e percepções de grupos. Além disso, é interessante que se repliquem estes tipos de estudos em diversos programas para fins de comparação de abordagens e de resultados com a finalidade de encontrar melhores evidências para tomada de decisão por parte de todos os usuários dessas informações.

\section{Referências}

Barth, T. G., Ensslin, S. R., \& Reina, D. R. M. (2012). Mestrado em contabilidade: uma investigação do perfil de pesquisador dos egressos. Registro Contábil - RECONT, 3(2), pp. 18-37.

Barth, T. G., Alberton, L., Camargo, R. C. C. P., \& Ensslin, S.R. (2015). Riscos de investimento pessoal na pós-graduação: contribuição para mensuração do custo-benefício educacional. Registro Contábil - RECONT, 6(2), pp. 14-33.

Becker, G. (1964). Human Capital: A Theoretical Analysis with Special Reference to Education, New York: Columbia University Press.

Ben-Porath, Y. (1967). The production of human capital and the life-cycle of earnings. Journal of Political Economy, v. 75, pp. 352-6.

Blaug, M. (1976). The empirical status of human capital theory: a slightly jaundiced survey. Journal of Economic Literature, v. 14, pp. 827-55.

Bortoluzzi, S. C., Ensslin, S. R., Ensslin, L., \& Valmorbida, S. M. I. (2011). Avaliação de Desempenho em Redes de Pequenas e Médias Empresas: Estado da arte para as delimitações postas pelo pesquisador. Revista Eletrônica Estratégia \& Negócios, 4(2). 
Brasil. Capes/MEC. Plano Nacional de Educação 2011 - 2020. Ministério da Educação. Brasília-DF, 2012. Recuperado em 14 julho, 2013 em: http://portal.mec.gov.br/index.php?option=com_ content\&id $=16478 \&$ Itemid $=1107$.

Castro, C. de M. (1977). A prática da pesquisa. São Paulo: McGraw-Hill do Brasil.

Centro de Gestão e Estudos Estratégicos - CGEE. (2012). Mestres 2012: estudos da demografia da base técnico-científica brasileira. Brasília, p. 24. Recuperado em: http://www.cgee.org.br. Acesso em 03 maio de 2013.

Chapman, B., \& Lounkaew, K. (2013). Introduction to the special issue on Economic Research for Education Policy. Economics of Education Review, v. 37, pp. 200-203.

Coates, H., \& Edwards, D. (2011). The Graduate Pathways Survey: New Insights on Education and Employment Outcomes Five Years after Bachelor Degree Completion. Higher Education Quarterly, 65(1). 1, pp. 74-93.

Creswell, J. W. (2010). Projeto de pesquisa: métodos qualitative, quantitative e misto. Tradução Magda Lopes. $3^{\text {a }}$ ed. Porto Alegre: Artmed, p. 296.

Cunha, J. V. A. (2007). Doutores em Ciências Contábeis da FEA/USP: análise sob a óptica da teoria do capital humano. $267 \mathrm{f}$. Tese de Doutorado em Ciências Sociais, Universidade de São Paulo, São Paulo, SP, Brasil.

Cunha, J. V. A. da; Cornachione JR, E. B., \& Martins, G. de A. (2010). Doutores em Ciências Contábeis da FEA/USP: análise sob a óptica da teoria do capital humano. Revista de Administração Contemporânea, n 3, pp. 532-557.

Dallabona, L. F., Oliveira, A. F. de, \& Rausch, R. B. (2013). Avanços pessoais e profissionais adquiridos por meio da titulação de mestre em ciências contábeis. Revista Contabilidade Vista \& Revista, 24(2), pp. 39-62.

Dickson, M., \& Harmon, C. (2011). Economic returns to education: What We Know, What We Don't Know, and Where We Are Going: Some brief pointers. Economics of Education Review, 30(6), pp. 1118-1122.

Dickson, M. R., \& Smith, S. (2011). What determines the return to education: An extra year or a hurdle cleared? Economics of Education Review, 30(6), pp. 1167-1176.

Ensslin, L., Ensslin, S. R., Lacerda, R. T. O. \& Tasca, J. E. (2010). ProKnow-C, Knowledge Development Process - Constructivist. Processo técnico com patente de registro pendente junto ao INPI. Brasil.

Ensslin, L., Ensslin, S. R., \& Pinto, H. de M.. (2013). Processo de investigação e Análise bibliométrica: Avaliação da Qualidade dos Serviços Bancários. RAC - Revista de Administração Contemporânea, 17(3), pp. 325-349.

Ensslin, S. R.; Ripoll-Feliu V. M., Ensslin, L., \& Dutra, A. (2014). .Performance evaluation to Support the University Management Activity. Pense e Journal (Paris), 76(8), pp. 2-17.

Frigotto, G. (2003). Educação e crise do capitalismo real. $5^{\mathrm{a}}$.ed. São Paulo: Cortez.

Gil, Antonio Carlos. (2002). Como elaborar projetos de pesquisa. 4a. ed. São Paulo: Atlas.

Lacerda, R. T. de O., Ensslin, L., \& Ensslin, S. R.. Uma Análise Bibliométricada literatura sobre Estratégia e Avaliação de Desempenho. Gestão \& Produção [online], 19(1), pp. 59-78, 2012. doi: 10.1007/ s11142-006-9006-z.

Lima, R. (1980). Mercado de trabalho: o capital humano e a teoria da segmentação. Pesquisa e Planejamento Econômico, Rio de Janeiro, 10(1), pp. 217-272.

Lordêlo, J. A., \& Verhine, R. E. (2001). O retorno do investimento em mestrado e doutorado para professores universitários: uma avaliação econômica da educação pós-graduada. Estudos em Avaliação Educacional, São Paulo, n. 24, pp. 165-186. 
Machin, S.; Stevens, M. (2004). The Assessment: Education. Oxford Review of Economic Policy, v. 20, n. 2, p. 157-172.

Machin, S. (2014). Economics of Education Research and Its Role in the Making of Education Policy. Fiscal Studies, 35(1), pp. 1-18.

Martins, G. A., \& Theóphilo, C. R. (2007). Metodologia da investigação científica para ciências sociais aplicadas. São Paulo: Atlas.

Martins, O. S., \& Monte, P. A. (2009a). Um Recorte da Produção Científica dos Egressos de um Programa de Pós-Graduação Stricto Sensu em Contabilidade. Revista Contemporânea de Contabilidade, Florianópolis, n. 12, pp. 127-150. ISSN 1807-1821

Martins, O. S.; Monte, P. A. do. (2009b). Mestres em Ciências Contábeis: uma análise sob a ótica da teoria do capital humano. Revista de Educação e Pesquisa em Contabilidade (REPeC), 3(2), pp. 1-22. doi: http://dx.doi.org/10.17524/repec.v3i2.65

Martins, O. S., \& Monte, P. A. do. (2010). Motivações, expectativas e influências relacionadas ao título de Mestre em Ciências Contábeis pelo Programa UnB/UFPB/UFPE/UFRN. Contabilidade, Gestão e Governança, 13(1), pp. 16-31.

Menon, M. E., Pashourtidou N., Polycarpou, A., Pashardes, P. (2012). Students' expectations about earnings and employment and the experience of recent university graduates: Evidence from Cyprus. International Journal of Educational Development, 32(6), pp. 805-813.

Mincer, J. (1958). Investment in human capital and personal income distribution. Journal of Political Economy, v. 66, pp. 281-302.

Oecd Iindicators. Education at a glance 2012. OECD Publishing. Recuperado em 2 julho, 2013, de http:// dx.doi.org/10.1787/eag-2012-en.

Oreopoulos, P., \& Salvanes, K. G. (2011). Priceless: The nonpecuniary benefits of schooling. Journal of Economic Perspectives, 25(1), pp. 159-184. doi:1 0.1080/00313831.2010.493344

Pozzebon, M. \& Freitas, H. M. R. de. (1998). Modelagem de Casos: Uma Nova Abordagem em Análise Qualitativa de Dados? Anais do Encontro Nacional da Associação Nacional de Pós-graduação e Pesquisa em Administração, v. 37, Foz do Iguaçu-PR, Brasil, 22.

Robeyns, I. (2006). Three models of education: rights, capabilities and human capital. Theory and Research in Education, 4(1), pp. 69-84. doi: 10.1177/1477878506060683

Salvato, M. A., Ferreira, P. C. G., \& Duarte, A. J. M. (2010). O impacto da escolaridade sobre a distribuição de renda. Estudos Econômicos, São Paulo, 40(4), pp.753-791

Schultz, T. W. (1961). Investment in human capital. The American Economic Review, Cambridge, 51(1), pp. 1-17.

Semaan, G. S., Cruz, M. D., Brito, G. A. de M., \& Ochi, L. S. (2012). Proposta de um Método de Classificação Baseado em Densidade para a Determinação do Número Ideal de Grupos em Problemas de Clusterização. Journal of the Brazilian Computational Intelligence Society, 10(4), pp. 242-262.

Silva, R. V., Ensslin, S. R., Ripoll-Feliu, V.M., \& Soler, C. C. (2014). E-government and Public Accounting Information: Bibliometric and Systemic Analysis. International Research Journal of Finance and Economics, 1(122), pp.76-91, ISSN: 1450-2887

Tasca, J. E., Ensslin, L., Ensslin, S. R., \& Alves; M. B. M. (2010). An approach for selecting a theoretical framework for the evaluation of training programs. Journal of European Industrial Training, 34(7), pp. 631-655. 